\title{
Homicídios de Adolescentes: Refletindo sobre Alguns Fatores Associados
}

\author{
Sergio Kodato \\ Ana Paula Soares da Silva \\ Universidade de São Paulo/Ribeirão Preto
}

\begin{abstract}
Resumo
Este estudo é uma investigação de alguns fatores associados a homicídios praticados contra adolescentes, no município de Ribeirão Preto (SP), onde, no período de 1995 a 1998, foram assassinados 101 adolescentes. A coleta e a análise dos dados foram realizadas através da conjunção das seguintes técnicas: levantamento de dados sociográficos, através da análise dos processos judiciais instaurados no Ministério Público local; observação participante da instituição de internamento no município, destinada para adolescente autor de ato infracional; entrevistas com adolescentes internos pela prática de homicídio $(n=8)$. Como resultado, pode-se afirmar que as condições de vida que levaram à morte os adolescentes, são fruto de uma sincronização de fatores, onde, além da fragilidade institucional, observa-se como determinantes a disputa pela apropriação de bens materiais, o conflito de interesses financeiros, o tráfico de drogas, e, um modo de relacionamento interpessoal, cuja resolução de situações conflitivas se dá de forma não mediada e violenta.

Palavras-chave: Homicídio; adolescência; violência; tráfico de drogas.
\end{abstract}

Adolescents' Homicide: Thinking about Some Associated Factors

Abstract

This research is an investigation of some factors associated to homicides committed against adolescents, at the city of Ribeirão Preto (SP), in which, during the period of 1995-1998, 101 children and adolescents were killed. The collect and analysis of data were made throughout the association of the following methods: sociographics data enrollment, analysis of taken lawsuits in the local prosecuting counsel; participant observation of the local internment institution, destined to adolescents authors of infraction acts; interview with intern adolescents for homicide acts $(n=8)$. As a result one may state that the life conditions that ends on death of adolescents are product of a synchronization of factors, where, besides the fragility of institutions, one may observe determinants the dispute for appropriation of goods, conflict of financial interests, drug traffic and, a mode of producing of interpersonal relationship, of which resolution of conflictive situation materializes in non mediate and violent ways.

Keywords: Homicide; adolescence; violence; drug traffic.

As demandas da sociedade civil por maior segurança e melhores condições de vida contrastam com a miséria crescente e a multiplicação das ocorrências de violência em todas as esferas da vida social. A dificuldade dos aparelhos de Estado em conter ou amenizar o incremento do crime, dos atentados ao patrimônio e à própria integridade física do cidadão comum, acabam por colocar segmentos significativos da população em estado de pânico e temor.

Se, como coloca Adorno (1995, p. 303), "a história da sociedade brasileira pode ser contada como uma história social e política da violência", o recrudescimento da criminalidade geral e a multiplicação de suas faces e dimensões, atingindo em especial e inexoravelmente

Endereço para correspondência: Departamento de Psicologia e Educação, FFCLRP/USP, Av, Bandeirantes, 3900, Cidade Universitatria, Ribeirão Preto, SP, 14040-901. E-mail: skodato@hotmail.com crianças e adolescentes, possibilitam dizer que se está diante de uma nova fase dessa história. Uma fase de mudança quantitativa e qualitativa, caracterizada pelo aumento e agravamento dos episódios de violência. Uma fase de crise no processo civilizatório, onde impera a lei do mais forte, numa tragédia fáustica, que exige esforços consideráveis no sentido de atenuar e sublimar os efeitos desse mal.

Esta investigação incursiona por esse campo intrincado da manifestação cotidiana da violência e, em especial, da sua última conseqüência, o homicídio. Os dados foram coletados na cidade de Ribeirão Preto, que se localiza na região nordeste do Estado de São Paulo, situando-se a 319 quilômetros da capital. Em 1996, a cidade contava com 456.252 habitantes (Prefeitura Municipal de Ribeirão Preto, 1998).

A escolha de Ribeirão Preto justifica-se pelo fato de que, nesta cidade, o índice de homicídios apresenta uma 
elevação crescente nos últimos anos. Segundo dados da Fundação SEADE (1999, wmw.seade.gov.br), no início da década atual, este índice, para cada 100.000 habitantes, era de 15,89 (em 1991). Em 1998, ele chega a alcançar 43,64. Durante este período, os dados disponíveis indicam ainda os seguintes valores: 18,08 em 1994, 41,68 em 1996 e 37,54 em 1997. Como se percebe, a partir de 1994, o índice dobra, aproximando-se, por exemplo, daqueles relativos à cidade de São Paulo, no início da década, que de 44,79 em 1991, e, 44,90 em 1994, saltou para 55,56 em 1996 e 54,76 em 1997 (Fundação SEADE, 1999). É importante notar que o maior aumento no índice de homicídios, em Ribeirão Preto, ocorreu entre 1994 e 1996, sendo que, se comparado com São Paulo, nesta última cidade, o aumento, no mesmo período, não ocorreu de forma tão acentuada. Esse é um fenômeno que merece atenção: nos grandes centros urbanos, a criminalidade violenta vem aumentando consideravelmente nas últimas décadas. As informações a respeito da cidade de Ribeirão Preto demonstram que tal fato também vem ocorrendo em cidades de médio porte.

Em relação à população jovem, os índices de mortalidade por homicídio não são tão elevados quanto os da população em geral. Considerando-se o período de 1995 a 1998, registrou-se, na cidade, o assassinato de uma criança (onze anos) e de cem adolescentes (doze aos dezoito anos). Segundo levantamento divulgado pela Delegacia de Investigações Gerais (DIG) do município (Eblak, 1998), os homicídios de menores de dezoito anos representam 20,3\% do total de homicídios na cidade. Em 1995, a população até os dezenove anos de idade representava $18 \%$ do total da população no município (Fundação SEADE, 1999). Ou seja, os adolescentes são assassinados numa proporção pouco maior do que aquela relativa à participação na população.

Entretanto, tal fato não minimiza a gravidade do problema em Ribeirão Preto, principalmente, se considerarmos que a velocidade de crescimento do homicídios, para esta faixa etária, é ainda maior do que a da população em geral. Por exemplo, em 1995, foram registrados, na cidade, sete assassinatos de adolescentes. Este número aumentou 315\%, atingindo, em 1996, o total de 29 homicídios. É esta escalada da violência contra os jovens que apresenta uma situação semelhante à verificada nas cidades de grande porte do terceiro mundo. De acordo com Zaluar (1995, p. 397), “...os jovens brasileiros de 15 a 18 anos morrem mais de assassinato do que de qualquer outro motivo".

Contudo, não é este o fato que mais vem chamando a atenção dos diferentes segmentos sociais. E participação do adolescente em atos violentos e não o seu processo de vitimização que mobiliza opiniões e solicitação de intervenção. E neste tocante, os dados sobre a autoria de homicídios por jovens parece vir de encontro com as especulações. Pelo menos o número de processos registrados no município aponta para um crescente aumento. De acordo com Silva (1999), que realizou um levantamento de processos de adolescentes autores de atos infracionais que tiveram envolvimento com o Juizado da Infância e Juventude no município, durante o período 1984 a 1996, foi o homicídio doloso a infração que mais cresceu, aumentando 40 vezes.

Considerando-se o processo de aumento no número de homicídios no município, tanto os praticados pelos adolescentes como aqueles em que eles figuram como vítimas, que fatores estariam neste fenômeno articulados? Quem são os adolescentes vítimas dos homicídios atuais? Por quais motivos, em que circunstâncias e por quem são cometidos tais assassinatos? Haveria associações entre a prática de atos infracionais, a passagem por instituições de internamento e a vitimização?

A fim de levantar indícios que possibilitem melhor refletir e compreender estas e outras questões é que foi realizado este trabalho. Pretende-se, com ele, a partir do conhecimento de determinadas condições que contribuem para a ocorrência dos homicídios, fornecer subsídios para a possibilidade de ações preventivas e/ou remediativas que atenuem o problema.

\section{Método}

\section{Participantes}

Cento e um processos instaurados no Ministério Público, visando a apurar os homicídios de adolescentes, no período de 1995-98, foram analisados e classificados.

Oito adolescentes internados por prática de homicídio na Unidade Educacional da FEBEM, situada em Ribeirão Preto (UE-03), foram entrevistados. Os adolescentes eram todos do gênero masculino, oriundos de Ribeirão Preto, com faixa etária dos 13 aos 17 anos. Os adolescentes foram escolhidos de acordo com a disponibilidade em participar da pesquisa, dentre os internos por homicídio.

\section{Material}

As entrevistas foram gravadas em fita K-7 e transcritas na íntegra. Foram ainda utilizados: um diário de campo, onde se anotavam as observações do pesquisador acerca da instituição de internamento e, uma ficha destinada ao levantamento de dados a respeito das vítimas de homicídios, utilizada na coleta de informações contidas nos 101 processos instaurados no Ministério Público local, 
em virtude do assassinato de adolescentes ocorridos entre 1995 e 1998.

\section{Procedimentos}

Como se observa, nesta investigação, recorreu-se ao inter-método que permite a articulação entre a pesquisa quantitativa e a qualitativa, sendo portanto a coleta e a análise dos dados realizadas através da conjunção das seguintes técnicas: 1) levantamento de dados sociográficos, através da análise dos processos judiciais instaurados no Ministério Público local, em função dos homicídios ocorridos $(n=101)$; 2) observação participante da instituição de internamento no município, destinada para adolescente autor de ato infracional (FEBEM/RP, UE03); e, 3) entrevistas com alguns dos adolescentes internos pela prática de homicídio $(n=8)$.

Com relação ao levantamento sociográfico, objetivando-se a busca das regularidades, empreendeuse a coleta de informações que pudessem ser quantificadas. Foram levantadas e classificadas informações referentes a: a) dados pessoais, como idade, local de residência ocupação, escolaridade, naturalidade, responsável, etnia e envolvimento com tráfico, b) dados sobre o homicídio, contendo informações sobre local de ocorrência, distrito policial, a forma como ocorreu o crime, a qualificação e situação do homicida, versão do Boletim de Ocorrência e outras versões surgidas ao longo do inquérito policial, bem como o desfecho do processo, c) dados sobre internação, investigando-se, nos casos onde as vítimas tiveram passagens pela FEBEM, o número de vezes em que estiveram internadas, o número de dias que permaneceram na instituição, a quantidade de fugas e se saíram ou não da instituição com a definição de outra medida, como a liberdade assistida.

Quanto à utilização das técnicas de observação na instituição de internamento e de entrevista com os adolescentes internos pelo cometimento de homicídios, a mesma foi requerida quando do levantamento dos dados sociográficos. Dentre as vítimas às quais constavam informações sobre a internação, número significativo havia passado pela FEBEM, o que indicava que os homicídios poderiam estar realmente vinculados ao mundo da delinqüência e, consequentemente, também às instituições encarregadas de coibi-la ou remediá-la.

As observações foram realizadas durante um período de seis meses, distribuídas em duas visitas semanais à instituição. Cada visita durava em média três horas. Após a visita, anotava-se no diário da campo as observações feitas pelo pesquisador. Neste trabalho, foram utilizadas as observações relativas à proposta pedagógica da instituição destinada aos adolescentes autores de homicídio.
As entrevistas foram semi-abertas, baseadas em roteiro estruturado em torno dos atos infracionais cometidos pelos entrevistados, principalmente os homicídios. As entrevistas foram realizadas individualmente, na própria instituição de internamento, durando em média 60 minutos. Cada adolescente foi entrevistado uma única vez.

\section{Resultados}

\section{Levantamento Sociográfico dos 101 Processos}

Pode-se afirmar que a maior parte da amostra é oriunda das camadas pobres da população. Embora não haja a disponibilidade de dados quantitativos sobre a renda das famílias, é a conjunção das informações que permite esta afirmação. Baixa escolaridade, desemprego, baixa qualificação profissional dos responsáveis e condições de moradia são exemplos de elementos que compõem esta configuração.

Os dados sobre o local de residência das vítimas mostram que a maior parte $(75,24 \%)$ residia nas regiões Norte e Oeste do município, setores de maior concentração populacional. Segundo dados da Prefeitura Municipal (1998), nestas regiões, em 1996, residia 74,55\% da população do município. Também foram essas regiões que centralizaram a maior parte dos homicídios $(78,22 \%)$.

Com relação à escolaridade, os resultados indicam que as vítimas possuíam baixo nível de instrução, sendo que a maioria, $41,96 \%$, situou-se na faixa de primeira a quarta série. Pode-se citar que, em relação ao primeiro grau, $10,89 \%$ cursou até a segunda série, $11,88 \%$ até a quinta série e, apenas 3,96\% cursou até a oitava série. Geralmente, o abandono da escola ocorre entre os doze e quatorze anos, faixa etária que marca o início do envolvimento com os atos infracionais.

Quanto à idade, a maioria $(58,41 \%)$, quando do falecimento, situava-se na faixa dos 16-17 anos. Esta porcentagem eleva-se para $84,15 \%$ quando considera-se a faixa que compreende dos 15 aos 18 anos de idade. Com relação a etnia das vítimas, as porcentagens distribuem-se da seguinte forma: 45,54\% de brancos, $53,46 \%$ de negros e pardos e, $0,99 \%$ sem informação.

A distribuição de acordo com o gênero ratifica a masculinização do mundo do crime, e em particular do crime organizado, como discutido por Zaluar (1996). Dentre as vítimas, $94,06 \%$ era do gênero masculino e apenas 5,94\% $(\mathrm{n}=6)$ do feminino. Quando se considera o gênero dos autores dos homicídios, apenas em um dos casos verifica-se a presença e autoria de uma mulher.

Nascidas na maioria $(68,32 \%)$ em Ribeirão Preto, as vítimas, em grande parte, não contavam com a figura de um ou mesmo de nenhum dos genitores. Dos casos em 
que se obteve informação sobre os responsáveis pelo adolescente $(n=76), 78,95 \%$ enquadram-se nesta categoria. Apenas 21,05\% das vítimas tinham o pai e a mãe como responsáveis. Na maioria $(52,63 \%)$, a mãe era a única responsável e, em 13,16\%, a responsabilidade do adolescente estava a cargo somente do pai. No primeiro caso, grande parte da ausência da figura paterna se deu por separação ou morte ou, pelo fato do pai ter abandonado a família e estar entregue, por exemplo, ao alcoolismo. Os demais casos (13,16\%) distribuem-se entre aqueles que estavam sob a responsabilidade de avós, irmãos, tias e guardiãs.

A ocupação das vítimas era diversificada entre serviços gerais, servente de pedreiro, chapa, ajudante de bar, balconista, etc. Todas as atividades caracterizam-se pela não exigência de qualificação ou grau de escolaridade. $\mathrm{Na}$ realidade, o tráfico de entorpecentes parece ter sido a principal atividade econômica. Em muitos casos, com os proventos advindos dessa atividade, os adolescentes contribuíam para o orçamento familiar e alguns chegavam a sustentar suas famílias. Em outros, os adolescentes abandonaram a família e passaram a ter vida independente, morando na rua ou no próprio ponto de venda das drogas. A avaliação dos processos judiciais apontou, em meio a singularidades e peculiaridades, para ao menos uma constância: grande parte dos jovens vitimados apresentavam antecedentes infracionais e passagens pela Unidade Educacional da FEBEM de Ribeirão Preto (UE-03), particularmente antecedentes que envolvem a presença das drogas. Dos 41 casos em que foi possível obter a informação, 29 constavam que o adolescente possuía envolvimento com o narcotráfico, o que representa 70,73\% dos processos com informação.

Em relação ao uso de entorpecentes, em 11,88\% dos processos continha informação de que a vítima não fazia uso e, em 42,57\% dos processos havia informação de que a vítima usava maconha e/ou crack. Em grande parte dos processos não há informações precisas (45,54\%), mas apenas suposições de envolvimento com drogas.

Quanto ao antecedente de internação, como referido anteriormente, dos 84 casos com esta informação, 45 passaram pela FEBEM, permanecendo em média 116 dias. A menor permanência foi de um dia e, a maior, de 577 dias, alguns sendo inclusive encaminhados para a FEBEM da capital do Estado. Os dados sobre quantidade de vezes em que estiveram internados apresentam as seguintes distribuições: $35,56 \%$ teve uma passagem; $24,44 \%$ duas passagens; $24,44 \%$ três passagens $6,67 \%$ quatro e, $6,67 \%$ cinco passagens. Dentre esses adolescentes $(n=45), 55,56 \%$ empreendeu tentativas de fuga durante o período da internação. Por sua vez, no que diz respeito à desinternação, dos 41 casos com informação, apenas 16 saíram em liberdade assistida e um foi encaminhado para o Conselho Tutelar. Os outros 24 saíram da instituição sem aplicação de qualquer medida.

Os homicídios, quase totalmente, foram cometidos por arma de fogo (geralmente revólver calibre 38). Apenas três foram cometidos por arma branca (estiletes e faca): um contra uma vítima do gênero masculino, e dois, contra duas meninas, sendo um cometido pelo namorado e outro pela única mulher autora de homicídio.

Como observado acima, o local do homicídio geralmente coincide com a região de residência da vítima, bem como em determinados casos, a vítima figura, em outro processo analisado, como a autora do homicídio, caracterizando um movimento cíclico nesse processo, onde existe uma proximidade bastante forte entre as vítimas e os autores dos homicídios.

Geralmente, os homicídios seguem um mesmo padrão: dois indivíduos em uma moto, portando armas de fogo, saem à procura da vítima e quando a encontram, o passageiro descarrega sua arma sobre a mesma, empreendendo-se a fuga logo em seguida. Os motivos alegados para o homicídio, quando existentes nos processos, referem-se, na maioria, a dívidas contraídas em aquisições de entorpecentes, seguida por vingança, conflitos de natureza subjetiva e desentendimentos ocasionados por brigas anteriores. Por outro lado, existem casos de adolescentes mortos por engano, confundidos com outra pessoa. Em dois dos casos em que foi possível apurar a autoria do homicídio $(n=44)$, as vítimas foram reconhecidas pelos autores como mortas por engano. Este fato evidencia a situação de insegurança a que está submetida a população jovem moradora nos locais de maior incidência de homicídio, colocando-a numa posição de risco e vitimização.

A autoria do homicídio é conhecida em apenas $43,56 \%$ da amostra e, em 56,43\% ela é desconhecida. Ou não há outras informações (por exemplo, não haviam testemunhas), ou se impôs a lei do silêncio, ou ainda, as investigações não foram concluídas, indicando que a morosidade e inoperância da polícia legitimam a impunidade.

Em relação à idade do autor, é significativa a participação de menores de 18 anos. Dos 44 processos onde a autoria é conhecida, em 20 o homicídio foi cometido ou assumido apenas por adolescente, em 15 somente por maiores e, em nove, foi cometido por menores e maiores de idade. O número bruto de autores dos homicídios $(n=58)$ mostra que há uma equivalência entre o menor e o maior de idade: 29 eram menores e 29 maiores. De acordo com levantamento da D.I.G., 
citado anteriormente, $42 \%$ dos homicídios, registrados no ano de 1998, foram praticados por jovens com menos de 18 anos. Em nossa pesquisa, como se verifica, do total de autores identificados, 50\% são menores de 18 anos, chamando assim a atenção para o fato de que adolescentes estão sendo utilizados, seja como matadores, seja assumindo a autoria de um maior de idade. Os jovens assumem a responsabilidade em metade dos homicídios cometidos na cidade, e um número cada vez maior deles está sendo vítima de homicídio. Isto é evidência cabal de que os mecanismos de contenção e canalização da violência estão funcionando precariamente, em crise permanente de realização.

A polícia participa diretamente como autora em $4,9 \%$ dos homicídios, alegando estrito cumprimento da lei. Em outros, ela aparece como suspeita, apontada por familiares ou por algumas testemunhas. Em depoimentos de adolescentes internados na FEBEM, encontram-se também referências a espancamentos e constrangimentos sofridos quando surpreendidos pela polícia em via pública.

Quanto ao desfecho dos processos, a ausência de informações dificulta análises mais precisas. Em 48 processos, inexiste o relatório de conclusão dos fatos e, em 15 ainda não foram concluídos os inquéritos policiais. Em onze casos, foi decretada a prisão preventiva e em cinco, o indiciamento. Alguns casos foram arquivados pela morte do autor $(n=4)$ ou pelo autor estar foragido $(n=1)$. Outros, aguardavam a identificação do autor $(n=6)$. No caso de autores menores de idade conhecidos $(n=29)$, em dez processos aparece o encaminhamento para a Vara da Infância e Juventude e, em um houve a aplicação da internação.

Os poucos casos de declaração de prisão preventiva do indiciado indicam que não há efetivo interesse e vontade política para a apuração dos fatos. A maior parte dos inquéritos não é concluída pela morosidade, quase paralisação nas investigações, seja por falta de laudos periciais, seja talvez pela falta de equipamentos, viaturas e recursos humanos.

A Análise Institucional da FEBEM-RP e as Entrevistas com Adolescentes Homicidas

$\mathrm{Na}$ análise da instituição FEBEM-RP, verificou-se uma insuficiência nas práticas pedagógicas, apesar do esforço cotidiano dos agentes institucionais envolvidos. O período escolar é optativo, ao contrário do que determina o Estatuto da Criança e do Adolescente (ECA), em seu Artigo 123, e, distribui-se numa duração exígua de aproximadamente 50 minutos (a duração de uma aula no ensino regular), conseguindo resultados expressivos em alguns casos, mas não alcançando de forma efetiva o contingente de internados.

A ressocialização depende muito mais de esforços pontuais de profissionais da instituição e das particularidades de cada adolescente do que da existência e manutenção de um programa pedagógico articulado e consistente com os objetivos de uma internação, tal qual apregoa o ECA e as normas internacionais na área. Não há um programa claro e fundamentado com diretrizes, conteúdos e atividades, sendo o ócio a característica central na rotina de grande parte dos internos. Considerando-se que muitos adolescentes são internados por envolvimento com drogas, de acordo com dados da própria instituição, $90 \%$ dos internos foram ou são usuários, seria de se esperar, numa proposta psicopedagógica, a presença de intervenções que tratassem da dependência. A ausência de trabalhos como, por exemplo, o desenvolvido no formato de comunidades terapêuticas, deixa uma lacuna para aqueles adolescentes que porventura desejariam abandonar o uso das drogas. Ao contrário, a exemplo do que ocorre em outras instituições com a mesma característica, e de conhecimento público, há indícios que tratam da presença de drogas no estabelecimento. O cheiro de maconha é um destes indícios, registrados nos boletins internos da instituição. A guerra de grupos que controlam o tráfico manifesta-se também dentro da própria instituição, havendo internos de um pavilhão que não podem entrar em contato com internos de outros pavilhões: são os chamados espinhos. A instituição FEBEM parece estar portanto estacionada no nível da assistência psico-pedagógica, não realizando sua função sócio-educativa e, com isso, pouco contribuindo para a ressocialização, quando não agravando a conduta infracional.

Quanto às entrevistas realizadas com menores internos que cometeram homicídios, as análises apontam para uma boa capacidade de compreensão, raciocínio, iniciativa e também, de frieza nos momentos de tensão. As infrações geralmente começam com uso de drogas e pequenos assaltos, que segundo eles são motivados pela necessidade, mas realimentados pela ganância, fato semelhante ao relatado por Craidy (1998), sendo esta uma das características que, segundo a autora, distingue o infrator do menino de rua. Os homicídios geralmente são atribuídos a impulso incontrolável, atitude impensada, defesa no sentido de matar ou morrer, necessidade pelo fato da vítima do assalto ter reagido. Não se notam indícios de culpa com relação ao homicídio, havendo arrependimento em somente dois casos dos oito entrevistados. As armas são adquiridas com grande facilidade e os atentados são premeditados, geralmente envolvendo cúmplices. Demonstram familiaridade com 
a guerra de gangues: "de vez em quando a gente ia dar uns tiros nas bocadas dos outros". Relatam espancamentos e abusos sofridos quando detidos por policiais, que deixam seqüelas de ódio e ressentimento. Para alguns adolescentes entrevistados, polícia é pior que bandido. Queixam-se do ócio na FEBEM e têm ciência de que se não tomarem providência no sentido de mudança no estilo de vida, fatalmente encontrarão a morte. Segundo os próprios adolescentes, quem mata morre. Representam a violência como instrumento de intimidação e poder.

\section{Discussão}

O contexto social, no qual se desenrolaram os fatos, mostra um quadro de evidente pobreza. Cabe salientar que não se está aqui assumindo uma relação direta entre miséria e criminalidade. A criminologia crítica (Taylor, Walton \& Young, 1980), há muito, apontou com clareza que a questão fundamental é a produção das leis e a atuação enviesada das instituições de controle social da violência, "que só identifica como criminoso o delinqüente oriundo das classes populares" (Zaluar, 1996, p. 67). Tal reconhecimento, contudo, não exclui aquele relativo à existência de configurações infracionais ligadas determinadas classes sociais. E, na problemática estudada ou seja, homicídios, fica bastante clara a sua relação com as condições de extrema pobreza, bem como com os fatores a ela inerentemente vinculados, em especial, a busca por uma alternativa econômica e de sobrevivência encontrada por esta população no mundo do comércio das drogas.

A exposição aos estímulos e oportunidades de pequenos delitos e de envolvimento com o comércio das drogas parece ainda vinculada também à constituição familiar, ou melhor, à rede de apoio dos adolescentes, em especial, à ausência de figuras que possam exercer um papel de apoio e proteção à vulnerabilidade e ao risco. Na maioria dos casos, o envolvimento com o tráfico inicia-se num momento da vida onde a introdução ao mundo adulto apresenta-se de forma bastante contraditória. De acordo com Pinheiro (1997, p. 46)

"...muitos jovens tentam compensar a marginalidade aderindo as gangues de rua, enquanto outros se envolvem no tráfico de drogas. O crime se torna a maneira mais fácil e rápida de ter mobilidade social e canais 'respeitáveis' para tal mobilidade são cortados amplamente". Numa predestinação ao ilícito, a extrema pobreza e a falta de opções empurram o adolescente para a marginalidade a criminalidade, ao mesmo tempo em que ele ideologicamente capturado pelos sonhos de consumo e grandeza, veiculados pela mídia e valorizados socialmente como sinônimo de felicidade e sucesso.

Para Castro (1998, p. 18) “as construções identitárias da contemporaneidade apontam, também, na direção da radicalização do individual onde o sujeito apenas se reconhece na apoteótica realização dos ditames da cultura de consumo". A falta de condições dignas de sobrevivência, a frustração diante de tantas oportunidades virtuais de consumo são elementos para se pensar a prática infracional, de certa forma, enquanto uma conduta reativa. A atividade ilícita é perpetrada no sentido de suprir uma falta, uma carência no plano material e simbólico, busca desesperada de satisfação que acaba redundando em morte.

Como afirma Violante (1997, p. 58), “ao sair da infância, o Eu deve poder auto-investir e projetar-se no futuro, na esperança de ter, então alcançado seus ideais (...) Para constituir-se, o Eu exige realidade: prazer real, significação e reconhecimento advindo de, pelo menos, um outro Eu que lhe sirva de ponto de apoio, modelo identificatório e suporte de investimento...". Marcados por um momento em que a modernidade apresenta frutos impossíveis de serem alcançados, e, pela ausência de modelos que contrariem o dito popular que "o crime não compensa", o modelo identificatório dos adolescentes passa facilmente a ser o do traficante, poderoso e bem sucedido. Os dados de Silva (1999) são bastante representativos deste poder de atração. $O$ tráfico de entorpecentes é a segunda infração que mais cresce no período estudado pela autora, aumentando, em treze anos, 23,75 vezes.

A ausência de figuras significativas de autoridade parece assim agravar, em determinados casos, o relacionamento desses adolescentes com a lei e com a sua adaptação às instituições sociais. Por outro lado, nas famílias onde ocorre a ausência de um dos cônjuges, em geral, o menor é forçado muitas vezes a abandonar a escola e ingressar precocemente no mercado de trabalho, como forma de sobrevivência e auxílio na renda familiar. A necessidade alia-se à possibilidade de ganho substancioso e o menor é capturado para o furto ou para o pequeno tráfico de varejo, na função de "avião". Estando no meio do pequeno tráfico, insere-se num ambiente de consumo de álcool e drogas, onde ocorre um intenso comércio obviamente ilegal de armas, bicicletas e motos e, que lhe possibilita o contato com um mundo simbólico bastante marcado pela peculiaridade da atração do crime organizado. O consumo de drogas, constitui-se assim em uma das principais portas de entrada para os atos infracionais e para o tráfico. Adolescentes pobres dependentes passam 
a praticar pequenos delitos para pagar dívidas assumidas com o uso de substâncias entorpecentes. Aos poucos, assumem "bronca" de traficantes maiores, inserindo-se assim numa rede de conflitos e disputa de mercados. Dentro dessa dinâmica de vida comercial ilícita, de economia de troca conturbada, de intenso porte de armas, no convívio inter-grupal, é inevitável que os pequenos desacordos sejam resolvidos de forma violenta, intensificando-se até suas últimas conseqüências.

Nesse mesmo sentido, também os espaços vivenciados pelos adolescentes não oferecem condições para mudarem a trajetória de envolvimento com o crime. A amostra estudada é insuficientemente instruída, compondo o contingente de alunos repetentes que acabam evadindo-se, e muitas vezes sendo expulsos da escola. As medidas aplicadas àquelas vítimas com antecedentes infracionais, que tiveram passagem pelo Juizado da Infância e Juventude, por sua vez, também não foram suficientes para oferecer novos referenciais e possibilidades de re-significação do papel social desses adolescentes, nem mesmo, para impedir a internação. Uma vez internados, essa medida foi marcada pela inatividade, pelo ócio, não conseguindo cumprir assim o caráter sócio-educativo de reeducação. A maioria reincide e procura fugir da instituição ou, quando saem, retornam ao mundo do crime.

Com relação ao autor do homicídio, a maior parcela não é identificada pela morosidade nas investigações, sendo poucos os casos de efetivação da prisão do autor do homicídio. Além de dificuldades técnicas, articulam-se a falta de recursos materiais, a ausência de vontade política de setores da polícia que, capturados por determinados agenciamentos ideológicos, podem vir a entender a morte de adolescentes infratores como "higiene social". Ao mesmo tempo, há que se considerar que, quando ocorre a identificação, poucas são as possibilidades de resocialização destes autores, sejam eles adultos ou adolescentes. Cumprindo pena ou medida sócio-educativa em instituições com reconhecida dificuldade de efetivação de seu papel, numa cultura infracional e num contexto extremamente complexo de disputas, dificilmente os autores de homicídios conseguirão romper com o círculo repetitivo do fenômeno, podendo sempre ser a próxima vítima.

\section{Considerações Finais}

Em todos os atestados de óbito das vítimas, existe uma observação que sintetiza claramente uma trajetória existencial marcada pelo não: "não era eleitor, não era reservista, não deixou filhos, não deixou bens, teve morte Psicologia: Reflexão e Crítica, 2000, 13(3), pp.507-515 não natural". Desprovidos de condições dignas de sobrevivência, não assistidos em seus direitos elementares, não reconhecidos na singularidade de suas demandas, não tiveram os adolescentes a possibilidade de atingir a vida adulta. Não tiveram acesso às políticas sociais básicas, definidas enquanto prioridades no Art. 4 do ECA e, ao que tudo indica, não sofreram a ação das políticas de assistência social e nem das medidas de proteção (Incisos II e III, Art. 87 do ECA). Não puderam ainda beneficiarse efetivamente das medidas sócio-educativas, propostas no sentido de se evitar a escalada no mundo da delinqüência e de promover a re-socialização do adolescente. Em suma, as vítimas, na grande maioria, não tiveram condições infra-estruturais favoráveis ao desenvolvimento pleno, não receberam a assistência necessária, enveredaram-se pela delinqüência e incapacitados para a reabilitação social, continuaram a infracionar, acabando por ser mortas.

A forte presença da não possibilidade na vida destas vítimas, que poderíamos também denominar de incompletude, não é apenas uma característica que aparece de modo isolado. Ela articula-se ainda com o que identificamos como impotência e repetição. Incompletude, impotência e repetição marcam não apenas a trajetória individual, mas o fenômeno estudado como um todo.

Os processos não se completam, inexistindo informações e finalizações desde o abandono ou exclusão da vida escolar até o próprio inquérito que investiga o homicídio. Faltam dados, medidas e providências. Essa realização parcial indica o descaso com a efetiva recuperação e reintegração do adolescente. Se a prioridade na proteção, execução de políticas sociais e destinação preferencial de recursos públicos não está sendo executada, isto certamente implica numa deterioração maior ainda no nível de vida dos adolescentes, em especial dos provenientes de camadas pobres. Nesse sentido, podemos considerar os homicídios como decorrentes diretamente do fracasso das instituições que não cumprem com seu papel prescrito socialmente. Mais do que isto, algumas delas criminalizam ainda mais o adolescente, ao invés de lhe oferecer um atendimento adequado.

É exatamente nessa fragilidade das instituições e no alcance de resultados significativos, que repousa a outra faceta do fenômeno em questão, a impotência. Impotência no discurso e na prática. Em especial, impotência dos aparelhos de Estado diante do crime e tráfico organizados, cada vez mais equipados.

O aparecimento do crack, o seu consumo e a distribuição pulverizada por micro-traficantes, parece ter alterado sensivelmente a configuração da criminalidade 
no município. Os dados de Silva (1999) apontam para a utilização de armamento pesado por parte dos adolescentes, tais como metralhadoras e fuzis, indicando uma mudança qualitativa na história da delinqüência juvenil no município, nos últimos anos. Embora ainda a grande maioria dos autores de atos infracionais seja composta por aqueles que praticam atos leves e desprovidos de violência, esses adolescentes, paulatinamente, gozam de uma infra-estrutura e de um suporte logístico oferecido pelo crime organizado. E, no nível da produção de subjetividades, verifica-se, na cultura dos adolescentes envolvidos na prática de atos ilegais, um processo de glorificação do crime. Entre os institucionalizados, são aqueles que cometeram infrações pesadas, como homicídios e latrocínios, inseridos em uma estrutura de tráfico organizado, os que são mais respeitados e temidos, não apenas por outros adolescentes, mas também pelos monitores e coordenadores da instituição.

Neste universo simbólico, os adolescentes são colocados na linha de frente, não só do tráfico de varejo de entorpecentes, mas da guerra entre gangues, tanto assumindo crimes cometidos por maior imputável, quanto eles próprios cometendo o homicídio diretamente. Está em curso um processo de produção de mortes de jovens, que necessita ser manietado em algum elo de sua cadeia, uma vez que apresenta uma tendência de franco e cíclico crescimento.

As histórias dos adolescentes vitimados, excetuandose os casos de mortes por engano, aponta ainda para uma repetição de ocorrências, eventos premeditados. A leitura dos processos é uma repetição de fatos, uma produção em série: evolução do envolvimento da vítima com atos infracionais, apreensões pela polícia , passagens por instituições, presença do tráfico de entorpecentes, uso e porte de armamento pesado, matar e morrer.

Com certeza, neste processo onde adolescente mata adolescente, existe a mediação de adultos, seja através das quadrilhas, seja através das instituições que desvirtuam seu papel. $\mathrm{O}$ aumento no número de adolescentes que assumem a autoria dos homicídios é assustador. Mais do que isto, é indicativo de que anos de políticas e práticas institucionais e sociais mal conduzidas e eivadas de equívocos, geraram e repetiram, em determinados segmentos populacionais, como mecanismo de sobrevivência e canal de ascensão social, uma geração de adolescentes submetidos à vitimização e/ou à propensão à infração e ao delito.

Como conclusão, pode-se afirmar que a delinqüência e as condições de vida que levaram à morte os adolescentes, são fruto de uma sincronização de fatores, onde, além da fragilidade institucional, observa-se como determinantes a disputa pela apropriação de bens materiais, o embate de interesses financeiros e de comercialização de entorpecentes, e, um modo determinado de produção de subjetividades, cujo destaque pode ser dado à recorrência à resolução de conflitos de forma não mediada e violenta.

\section{Referências}

Adorno, S. (1995). A violência na sociedade brasileira: Um painel inconcluso em uma democracia não consolidada. Sociedade e Estado, 10, 299-342. Estatuto da Criança e do Adolescente. (1990). Diário Oficial da União. Lei no 8069, de 13 de julho de 1990. Brasilia, DF.

Castro, L. R. (1998). Infância e adolescência hoje. Em L. R. Castro (Org.), Infáncia e adolescência na cultura de consumo (pp.11-22). Rio de Janeiro: Infancia

Craidy, C. M. (1998). Meninos de rua e analfabetismo. Porto Alegre: ArtMed. Eblak, L. (1998, 6 de Dezembro). Adolescentes envolvidos em homicídios. Folha de São Paulo, 3, 1 .

IBGE. (1991). Censo demográfico - resultados do universo relativo às caracteristicas da populacãa e dos domicilios. Fundação Instituto Brasileiro de Geografia e Estatística. Brasilia, DF.

Pinheiro, P. S. (1997). Violência, crime e sistemas policiais em países de novas democracias. Tempo Social, 9(1), 43-52.

Prefeitura Municipal de Ribeirão Preto. (1998). Ribeirão Preto em Dados: $97 /$ 98. Ribeirão Preto: Edigma.

Silva, A. P. S. (1999). O jovem em conflito com a lei na cidade de Ribeirão Preto (SP): 1986 a 1996. Dissertação de Mestrado não publicada. Curso de Pós1986 a 1996. Dissertação de Mestrado não publicada. Curso de Pós-
Graduação em Psicologia, Faculdade de Filosofia, Ciências e Letras, Universidade de São Paulo. Ribeirão Preto, São Paulo.

Taylor, I., Walton, P. \& Young, J. (1980). Criminologia crítica. Rio de Janeiro: Edições Graal.

Violante, M.L.V. (1997). A perversidade da exclusão social. Em D. L. Levisky (Org.), Adolescencia e violência: Consequiências da realidade brasileira (pp. 5362). Porto Alegre: Artes Médicas.

Zaluar, A. (1995). Crime, medo e política. Sociedade e Estado, 10, 391-416. Zaluar, A. (1996). Crime e castigos vistos por uma antropóloga. Em M. C. L. Bingermer \& R. S. Bartholo (Orgs.), Violencia, crime e castigo (pp. 5584). São Paulo: Loyola. 
Sobre os autores:

Sergio Kodato é Psicólogo, Doutor em Psicologia pela Universidade de São Paulo, Professor do Curso de Psicologia da Universidade de São Paulo, Campus de Ribeirão Preto.

Ana Paula Soares Silva é Psicóloga, Pesquisadora do Centro de Investigações sobre

Desenvolvimento Humano e Educação Infantil (CINDEDI), Mestre em Psicologia e Doutoranda no Programa de Pós-Graduação em Psicologia na Faculdade de Filosofia, Ciências e Letras de Ribeirão Preto da Universidade de São Paulo, Ribeirão Preto, SP. 
Filiado ao Programa de Pós-graduação em Psicologia do Desenvolvimento - UFRGS

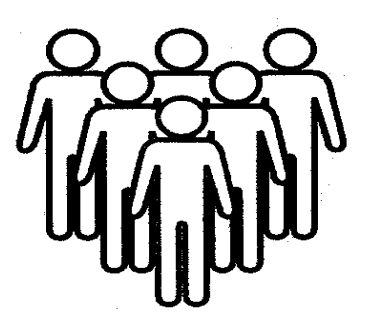

Congrega psicólogos e demais profissionais das áreas da saúde e educação interessados na investigação e compreensão dos transtornos do desenvolvimento e suas implicações para intervenção na comunidade, sob a coordenação da Profa. Dra. Cleonice Bosa

Os objetivos do NIEPED são: Desenvolver pesquisa sobre crianças e adolescentes que apresentam transtornos do desenvolvimento, com ênfase no comprometimento psicolingüístico e da interação social, e aspectos psicossociais; criar um banco informatizado de dados e referências bibliográficas sobre a área, disponível para pesquisadores, estudantes e profissionais interessados no assunto; incentivar o desenvolvimento e circulação de instrumentos de avaliação do comportamento da população estudada para fins clínicos, educacionais, e de pesquisa, bem como a elaboração de material bibliográfico destinado a professores, familiares e profissionais em geral; apoiar e subsidiar estudos e intervenções transdisciplinares, públicas ou privadas, com a finalidade de desenvolver programas educacionais e de qualificação profissional visando a melhoria das condições de vida dessas crianças/adolescentes e suas famílias; atuar no ensino da graduação e pós-graduação.

\section{NIEPED/UFRGS}

Instituto de Psicologia

Rua Ramiro Barcelos, 2600, sala 108

90035-003, Porto Alegre RS

Tel.: xxx 513165145

Fax: xxx 513304797 